\title{
SIGNIFICADOS DO FEMININO NO DISCURSO DE ALCOOLISTAS E A INTERFACE COM A SAÚDE MENTAL ${ }^{1}$
}

\author{
Helder de Pádua Lima², Violante Augusta Batista Braga33, Luciana Vieira de Carvalho4, Ana Caroline de \\ Oliveira Morais ${ }^{5}$
}

\footnotetext{
${ }^{1}$ Artigo extraído da dissertação - Grupo de auto-ajuda ao alcoolista como dispositivo da rede de apoio social, na Universidade Federal do Ceará (UFC), 2009.

${ }^{2}$ Mestre em Enfermagem. Enfermeiro do Centro de Atenção Psicossocial do município de Caucaia - CE. Ceará, Brasil. E-mail: padua_helder@hotmail.com.

${ }^{3}$ Doutora em Enfermagem. Professora Associado do Departamento de Enfermagem da UFC. Ceará, Brasil. E-mail: vivi@ufc.br

${ }^{4}$ Graduanda em Enfermagem da UFC. Bolsista CNPq. Ceará, Brasil. E-mail: lucianavcarvalho@yahoo.com.br

${ }^{5}$ Graduanda em Enfermagem da UFC. Bolsista de Iniciação Científica - Fundação Cearense de Apoio ao Desenvolvimento Científico. Ceará, Brasil. E-mail: carolzinha_om@hotmail.com
}

RESUMO: Diante do impacto causado pelo alcoolismo à saúde individual e coletiva, refletimos que, na sociedade na qual estamos inseridos, uma série de repercussões envolvendo o gênero feminino podem ser desencadeadas, inclusive no tocante à saúde mental. Objetivamos neste estudo apreender do discurso de alcoolistas os significados do feminino e a interface destes com a saúde mental. Estudo do tipo descritivo, com abordagem qualitativa, realizado com 20 sujeitos participantes de um grupo de Alcoólicos Anônimos de Fortaleza - Ceará. Os dados foram coletados através de entrevistas individuais, onde utilizamos um roteiro semi-estruturado, e analisados conforme o método de análise de conteúdo. Emergiram os seguintes significados: apoio social; sofrimento e adoecimento; passividade e submissão frente ao masculino. Concluímos que, os sentidos apreendidos constituem fatores relevantes no padrão dos riscos de saúde. Notamos que os processos sociais relativos ao gênero feminino repercutem na saúde mental.

DESCRITORES: Alcoolismo. Mulheres. Saúde mental

\section{MEANINGS OF THE FEMININE IN ALCOHOLIC DISCOURSE AND ITS INTERFACE WITH MENTAL HEALTH}

\begin{abstract}
Given the impact caused by alcohol to individual and collective health, we reflect that in the society to which we belong, a series of repercussions involving the female gender with regard to mental health may be revealed. The main objective in this study is to capture from the speech of alcoholics the meanings of the feminine and their interface with mental health. This is a descriptive study with a qualitative approach, involving 20 Alcoholics Anonymous participants from Fortaleza, Ceará, Brazil. The data was collected through individual interviews using semi-structured questions and analyzed according to the content analysis method. From such research, the following meanings emerged: social support; suffering and illness; passiveness; and submission to the male. The study concludes that perceived senses constitute relevant factors in the patterns of health risks. It is also noted that social processes related to the female gender cause repercussions in mental health.
\end{abstract}

DESCRIPTORS: Alcoholism. Women. Mental health.

\section{SIGNIFICADOS DE LO FEMENINO EN EL DISCURSO DE LOS ALCOHÓLICOS Y SU INTERFAZ CON LA SALUD MENTAL}

\begin{abstract}
RESUMEN: Al tener en cuenta el impacto causado por el alcoholismo para la salud individual y colectiva, se puede reflexionar que en la sociedad a la cual pertenecemos, una serie de efectos relacionados con la mujer pueden ser desencadenados, incluso en lo que se refiere a la salud mental. El objetivo principal de este estudio es captar en el discurso de los alcohólicos los significados de lo femenino y su interfaz con la salud mental. Se trata de un estudio descriptivo con enfoque cualitativo, realizado con 20 participantes de un grupo de Alcohólicos Anónimos en la ciudad de Fortaleza, Ceará, Brazil. Las informaciones se recolectaron a través de entrevistas individuales, con preguntas semi-estructuradas, y se analizaron según el método del análisis de contenido. De la investigación surgieron los siguientes significados: apoyo social; sufrimiento y enfermedad; pasividad y sumisión a lo masculino. Se concluye que los significados captados son factores relevantes en el patrón de riesgos para la salud. Se observa también que los procesos sociales relacionados con el género femenino tienen impacto en la salud mental.
\end{abstract}

DESCRIPTORES: Alcoholismo. Mujeres. Salud mental. 


\section{CONSIDERAÇÕES INICIAIS}

Estudos recentes têm esboçado a realidade no tocante ao uso de drogas psicoativas em âmbito nacional apontando o álcool como a droga mais consumida.

Exploramos o alcoolismo como conseqüência do uso abusivo de bebidas alcoólicas, entendendoo como uma doença crônica; com fatores genéticos, psicossociais e ambientais influenciando seu desenvolvimento e suas manifestações. A doença é geralmente progressiva, fatal, e caracterizada pela falta de controle sobre a bebida alcoólica, pré-ocupação com a droga e uso desta apesar das implicações adversas, além de distorções no pensamento e negação notáveis. Cada um destes sintomas pode ser contínuo ou periódico. ${ }^{1}$

O II Levantamento domiciliar sobre o uso de drogas psicotrópicas no Brasil, realizado em 2005, nas 107 maiores cidades do país, incluindo Fortaleza-CE, aponta que $12,3 \%$ das pessoas, com idade entre 12 e 65 anos, são dependentes de álcool; taxa essa superior à de $11,2 \%$, encontrada no I Levantamento, realizado em 2000. ${ }^{2-3}$

Epidemiologicamente, os transtornos relacionados ao uso de álcool afetam cinco vezes mais homens do que mulheres. Homens são acometidos em idade mais precoce, mas, uma vez portadoras do transtorno, as mulheres têm uma progressão mais rápida da doença. Ao longo dos últimos anos, as pessoas têm iniciado o consumo de álcool cada vez mais cedo, o risco de dependência tem aumentado e o padrão de uso de álcool e dependência entre as mulheres têm se tornado semelhante aos dos homens. ${ }^{4}$

O sentido do termo 'gênero', que adotamos nesse estudo, diferencia-se da palavra 'sexo'. A perspectiva de gênero vai ao encontro de papéis construídos social, cultural e historicamente; o que denota a realidade de que a situação e os papéis da mulher e do homem são construções sociais mutáveis.

Diante do impacto causado pelo alcoolismo à saúde individual e coletiva, apontamos as possíveis repercussões no gênero feminino, inclusive no tocante à saúde mental; compreendida como o estado de bem-estar no qual o indivíduo percebe as próprias habilidades, pode lidar com os estresses normais da vida, é capaz de trabalhar produtivamente e está apto a contribuir com sua comunidade. $^{1}$

Diante do exposto, questionamos: quais os significados do feminino contidos no discurso de alcoolistas e a repercussão desses na saúde mental? Com base nos questionamentos propostos, desenvolvemos esse estudo objetivando apreender do discurso de alcoolistas os significados do feminino e a interface destes com a saúde mental.

\section{PERCURSO METODOLÓGICO}

Desenvolvemos um estudo do tipo descritivo, com abordagem qualitativa, em um dos grupos Alcoólicos Anônimos (AA) de Fortaleza-CE, localizado no bairro Rodolfo Teófilo. Escolhemos o AA como cenário de pesquisa pelo fato de reconhecermos os grupos de auto-ajuda como dispositivos de apoio social ao alcoolista.

Os sujeitos do estudo foram representados por alcoolistas maiores de 18 anos que, independentemente do sexo, desejaram participar, encontravam-se afiliados ao grupo de auto-ajuda escolhido por, no mínimo, um ano, participavam regularmente das reuniões, e apresentavam condições físicas e emocionais para responder aos questionamentos.

Participaram do estudo 20 sujeitos. Definimos o número de participantes no decorrer da coleta de dados, através do critério de saturação de respostas. Iniciamos a coleta após a permissão do Comitê de Ética em Pesquisa da Universidade Federal do Ceará, protocolo no 198/08.

Coletamos os dados através de entrevistas individuais, realizadas durante dois meses no ano de 2008, em dois dias de cada semana. Utilizamos um roteiro semi-estruturado contendo perguntas fechadas acerca de dados sociodemográficos e questões norteadoras que resgatavam a história de uso de álcool, vivência no grupo e a influência desta no modo de vida do alcoolista.

Registramos as informações colhidas nas entrevistas com um gravador, sendo, posteriormente, transcritas na íntegra. Além disso, fizemos anotações em diário de campo para complementação das informações. Agrupamos os dados em duas categorias, intituladas 'Conhecendo os aspectos sociodemográficos dos sujeitos' e 'Os sentidos relativos ao feminino e a repercussão desses na saúde mental'. Os dados contidos em tais categorias foram analisados de acordo com o método de análise de conteúdo. ${ }^{5}$

Por fim, fundamentamos os resultados de acordo com a literatura encontrada, que abordava a temática em estudo, e publicada em livros textos, artigos científicos, manuais, dentre outras publicações que consideramos pertinentes. 
Realizamos o estudo de acordo com os preceitos éticos da Resolução 196/96 do Conselho Nacional de Saúde, que regulamenta a pesquisa envolvendo seres humanos. ${ }^{6}$ Aos participantes informamos o objetivo do estudo e a finalidade dos resultados. Também orientamos quanto ao anonimato e a sua autorização em participar do estudo, mediante a assinatura do Termo de Consentimento Livre e Esclarecido, e que poderia ser retirada no momento que desejassem.

\section{APRESENTAÇÃO E DISCUSSÃO DOS RESULTADOS}

\section{Conhecendo os aspectos sociodemográficos dos sujeitos}

Iniciamos a apresentação e discussão dos resultados obtidos, abordando os dados objetivos, de caracterização dos sujeitos, organizados na Tabela1.

Tabela 1 - Distribuição dos sujeitos segundo sua caracterização sociodemográfica. Fortaleza - CE, 2009

continua

\begin{tabular}{|c|c|}
\hline Características sociodemográfica & $f$ \\
\hline \multicolumn{2}{|l|}{ Idade (em anos) } \\
\hline $30-39$ & 2 \\
\hline $40-49$ & 4 \\
\hline $50-59$ & 7 \\
\hline $60-69$ & 7 \\
\hline \multicolumn{2}{|l|}{ Sexo } \\
\hline Masculino & 18 \\
\hline Feminino & 2 \\
\hline \multicolumn{2}{|l|}{ Escolaridade } \\
\hline Ensino fundamental incompleto & 6 \\
\hline Ensino fundamental completo & 2 \\
\hline Ensino médio completo & 8 \\
\hline Ensino superior completo & 1 \\
\hline Pós-graduação & 3 \\
\hline \multicolumn{2}{|l|}{ Naturalidade } \\
\hline Interior do Ceará & 4 \\
\hline Capital do Ceará & 13 \\
\hline Municípios de outros estados & 3 \\
\hline \multicolumn{2}{|l|}{ Profissão/Ocupação } \\
\hline Aposentado & 8 \\
\hline Autônomo & 4 \\
\hline Educador físico & 1 \\
\hline Serviços gerais & 3 \\
\hline Secretária & 1 \\
\hline Telefonista & 1 \\
\hline Serigrafeiro & 1 \\
\hline Funcionário público & 1 \\
\hline \multicolumn{2}{|l|}{ Residência } \\
\hline Própria & 16 \\
\hline Alugada & 4 \\
\hline
\end{tabular}

conclusão

\begin{tabular}{lr}
\hline Renda mensal (em salários mínimos no valor \\
de 380 reais) & 14 \\
1 - 2 & 3 \\
3 - 4 & 3 \\
5 ou mais & 12 \\
Situação conjugal & 4 \\
Casado & 2 \\
União estável & 2 \\
Solteiro & \\
Divorciado & 15 \\
Religião & 4 \\
Catolicismo & 1 \\
Protestantismo & \\
Ateísmo & 9 \\
Com quem mora & 2 \\
Cônjuge e filho (s) & 3 \\
Cônjuge, filho(s) e neto(s) & 1 \\
Sozinho (a) & 1 \\
Cônjuge, filho(s) e sogro (a) & 1 \\
Filho(s) & 3 \\
Cônjuge, filho(s) e genros & 5 \\
Cônjuge & 5 \\
Número de filhos & \\
1 & \\
2 &
\end{tabular}

De acordo com a Tabela 1, os participantes tinham idade entre 30 e 69 anos, sendo dezoito homens e duas mulheres.

Em relação à idade e ao gênero, tanto o uso de álcool, como a prevalência de dependência a este no Brasil, tem sido maiores entre os homens em todas as faixas etárias estudadas, a partir de doze anos de idade. ${ }^{7}$

A presença maior de uso de álcool e alcoolismo entre homens é um achado que vem sendo consistentemente descrito, cuja causa ainda não está devidamente esclarecida. As hipóteses elaboradas em diversos aspectos (biológicos, culturais, sociais e econômicos) têm considerado o papel da mulher na sociedade, a identificação da virilidade com hábito de beber, a utilização do álcool como ansiolítico entre os homens e o estigma que cerca o consumo de álcool em mulheres.

O beber feminino, por sua vez, engloba um conjunto de fatores relacionados ao ser mulher no espaço social e ser mulher alcoolista, numa relação dialética entre o plano identitário e os processos de subjetivação hegemônicos de gênero, onde a questão da violência doméstica se apresenta de forma significativa. Assim, o beber feminino relaciona-se com o processo de lidar com experiências adversas e fugir do sofrimento, resistindo à violência e ao 
desamparo, numa tentativa de ficar alegre e mais sociável; assim como num comportamento de isolamento social, depressivo e autodestrutivo. ${ }^{8}$

Além disso, as mulheres apresentam menos apoio da família ou amigos para iniciar um tratamento do que os homens, e as perdas pessoais, sociais e profissionais sofridas mostram-se preditivas para a entrada no tratamento. ${ }^{9}$ Entre os entrevistados, doze estavam casados; quatro, em união estável; dois, solteiros e dois, divorciados; três moravam sozinhos e dezessete conviviam com familiares. Todos tinham filho(s).

Os familiares do alcoolista podem representar fonte significativa de apoio social. Este suporte pode ser instrumental (financeiro, por exemplo) e/ou emocional, referente à afeição, preocupação com o outro e ações que levam a um sentimento de aprovação e de pertencer a determinado grupo.

Ao mesmo tempo, o alcoolismo pode constituir-se como um dos maiores problemas para as famílias, as quais demonstram pouco conhecimento sobre o mesmo. Entre as maiores dificuldades enfrentadas estão a violência intrafamiliar e as relações conturbadas. ${ }^{10}$

Dos participantes, quinze eram católicos; quatro, protestantes; e um não tinha práticas religiosas. Várias dimensões da religiosidade (afiliação religiosa, frequencia a cultos, autoavaliação quanto à religiosidade, e educação religiosa na infância) relacionam-se com o uso de drogas, com possível efeito inibidor. Porém, é difícil identificar qual dimensão da experiência religiosa é mais significativa para a modulação do uso de álcool e outras drogas, devendo ser considerados, também, aspectos como: importância atribuída à religião na vida; envolvimento religioso; medidas de crença religiosa (crença em deus, intensidade da fé, etc.); práticas religiosas pessoais (orações solitárias, leituras religiosas, etc.); participação em atividades da igreja além dos cultos; tempo gasto com atividades religiosas; e crenças e valores religiosos. ${ }^{11}$

Todos os participantes procediam de bairros do município de Fortaleza, geralmente próximos ao grupo de auto-ajuda onde realizamos o estudo, sendo que treze eram naturais deste município, e os demais, de outros municípios. Este fato pode ser explicado com base na existência de muitos núcleos de AA, distribuídos na maioria dos bairros da cidade, o que favorece o acesso e a participação em grupos próximos à residência dos alcoolistas.

Em relação à escolaridade, oito sujeitos iniciaram o ensino fundamental, mas destes, apenas dois concluíram; oito participantes haviam concluído o ensino médio; um possuía ensino superior e três tinham pós-graduação. Quanto à profissão/ocupação, oito eram aposentados e quatro, autônomos; entre os demais havia um educador físico, uma secretária, uma telefonista, um funcionário público, três trabalhavam com serviços gerais (pinturas, desenhos e vigilância) e um, era serigrafeiro.

Quanto à renda mensal, quatorze sujeitos ganhava até dois salários mínimos; três, entre três e quatro; e outros três participantes tinham remuneração acima de cinco salários mínimos. Dezesseis residiam em habitação própria e quatro em moradia alugada.

Esses achados mostram que o consumo de álcool tem se disseminado em diversas camadas sociais e que o alcoolismo tem acometido pessoas com diferentes níveis de escolaridade, remuneração e profissão/ocupação. Sabemos que a escolaridade influencia na profissão/ocupação de uma pessoa e, consequentemente, na sua remuneração. Os baixos preços de bebidas alcoólicas no país, em geral, o fácil acesso em vários pontos de venda e a percepção sobre o consumo de álcool são fatores que favorecem as pessoas estarem, igualmente, expostas e vulneráveis.

\section{Os sentidos relativos ao feminino e a reper- cussão desses na saúde mental}

Nos relatos dos sujeitos identificamos 75 passagens alusivas ao feminino. Nas mesmas foram citadas pessoas de convívio familiar (companheira, filha, mãe e irmã) e esporádico (amiga, profissional da saúde, dentre outras). Nas falas, emergiram os seguintes significados: apoio social, sofrimento e adoecimento, ; passividade e submissão frente ao masculino.

Identificamos o feminino como apoio social no decorrer do processo saúde-doença do alcoolista em 39 passagens nos discursos dos participantes, os quais remetiam à uma maior sensação de bem-estar e aos cuidados ofertados.

Os trechos a seguir ilustram os achados:

[...] aí o médico de lá disse só pra minha irmã, não disse pra mim, que ela me levasse no AA, que ela procurasse um, aí ela me levou (Participante 17).

[...] hoje posso entrar dentro de casa e abrir a panela na casa da minha mãe e colocar comida pra mim, e eu tinha perdido esse direito. Hoje sou feliz, não brigo com a esposa, o pessoal me respeita. O AA me devolveu a confiança, valorizou minha vida. Dependo daqui. Minhas irmãs, mãe, mulher me apóiam (Participante 6). 
[...] no dia dos pais agora que passou eu estava num shopping almoçando com minha esposa e minhas filhas. Tinha gente nas mesas do lado, com aquelas torres de chope e eu percebi pela primeira vez como aquele momento estava sendo legal. E eu não estava precisando beber, nem de drogas pra ter diversão. Minha filha hoje não se treme mais. Hoje faço academia com minha esposa, nós dois juntos. Tenho alegrias, tenho minhas filhas... (Participante 4).

O apoio social mencionado consiste em sistemas de suporte que proporcionam assistência e encorajamento para que os sujeitos com inaptidão física ou emocional possam melhor superá-la. ${ }^{1}$

Esse apoio é o suporte emocional ou prático dado na forma de afeto, companhia, assistência e informação, tudo que faz o indivíduo sentir-se amado, estimado, cuidado, valorizado e seguro contribui para a sensação de coerência da vida e o controle sobre a mesma e traz benefícios não só para quem o recebe, na forma de informação ou auxílio, mas também para quem o oferece. As pessoas necessitam umas das outras e, por isso, quando o apoio diminui, há um comprometimento do sistema de defesa do corpo. A sensação de não poder controlar a própria vida, juntamente com a sensação de isolamento, podem ser relacionadas com o processo de saúdedoença, aumentando a suscetibilidade individual para transtornos mentais, por exemplo.

Apontamos o apoio social como um moderador diante do impacto negativo de acontecimentos de vida que implicam um nível elevado de estresse, tendo um efeito protetor perante tais acontecimentos, entre os quais se inclui a doença. Pensamos que o suporte social afeta a saúde quando influencia as emoções, cognições e comportamentos. Quanto à saúde mental, consideramos que o apoio social possibilita a manutenção da regulação dos sistemas de resposta, prevenindo, assim, respostas extremas e disfuncionais. ${ }^{12}$

Dessa forma, o suporte social afeta diretamente a saúde mental e funciona como mediador do estresse, modificando o seu efeito, ou seja, o indivíduo que conta com alto nível de apoio social reage mais positivamente às situações estressantes se comparado a outros que não dispõem deste tipo de recurso. ${ }^{13}$

No contexto do alcoolista, tal apoio pode ser providenciado por amigos, familiares, profissionais dos serviços de saúde, igrejas, grupos e outros. Todos esses agentes e cenários constituem dispositivos que compõem sua rede de apoio social que atua de forma a eliminar barreiras, ; manter os vínculos sociais do alcoolista ; e fortalecer os laços de solidariedade. ${ }^{14}$
A oferta de apoio ao alcoolista, por exemplo, é um componente significativo no processo de tratamento, mas que nem todas as pessoas são igualmente habilidosas em ofertá-lo. O gênero feminino pode se destacar nessa oferta por, historicamente, relacionar-se com a provisão do cuidado, inclusive nas situações de adoecimento.

Em sociedades que equiparam poder, sucesso e força como características masculinas, os homens geralmente buscam, no processo de socialização (pela mídia, entre pares, na família), o distanciamento de características relacionadas ao feminino: sensibilidade, cuidado, dependência, fragilidade. Estas atribuições simbólicas diferenciadas entre homens e mulheres resultam, muitas vezes, para os homens, em comportamentos que os predispõem a doenças, lesões e mortes. ${ }^{15}$

Assim, o gênero masculino depende do feminino, por exemplo, no cuidado à saúde e obtendo fatores de proteção relativos a uma variedade de agravos e doenças. Porém, isso pode não acontecer da mesma forma no sentido inverso, ou seja, para o gênero feminino.

Dezoito passagens dos discursos dos sujeitos continham, por exemplo, correlação do feminino com sofrimento e adoecimento. Apresentamos alguns desses trechos a seguir:

[...] meu casamento acabou por causa do alcoolismo dele. Ele me traiu com minha própria irmã. Eu nem bebia, mas fui beber pra esquecer e odiei aquele gosto, mas lembro que passou a dor que estava sentindo. Com uns dois anos depois eu já estava sentindo coisa errada, porque comecei a fazer besteiras que eu nunca na minha vida ia imaginar. Minhas filhas viam as minhas brigas com o pai delas em casa, eu abandonei praticamente. Mas minha mãe e minha irmã mais velha me ajudaram, sempre cuidaram delas três. Pra quem teve as filhas como eu tive, assistindo o pai delas me espancar dentro de casa [...]. Elas chegaram a um ponto que não me chamavam mais de mãe e eu recuperei isso (Participante 11).

[...] tirei uma moça da família dela e me casei com ela. Ela se preocupou muito comigo enquanto estávamos casados. Ela tinha pavor de assistir ao jornal na televisão e meus filhos também. Como eu trabalhava viajando muito naquela época, ela sempre tinha medo de receber a notícia de que eu havia morrido, através da televisão. Ela não assistia jornal, sei que quando saia de casa a preocupação dela aumentava porque eu ia beber. Eu andava armado, era prepotente. Essa era minha cabeça de alcoólico. Ela via que eu corria risco. Sei que a fiz sofrer por isso, não por agressão física ou verbal, nada disso (Participante 2). 
[...] eu to muito nervosa, eu não era assim. É tão chato uma família estar todo dia com confusão. Hoje lá em casa ta assim. Mas já é a quarta vez que meu filho bebe e causa confusão. Nesse final de semana eu precisei amarrar ele em casa porque não sei o que teria acontecido se não tivesse feito isso. Mas também não sei o que fazer. Ainda não conversei com ele depois disso, mas quando eu estiver mais calma e serena vou conversar com ele sobre isso e até quem sabe fazer uma abordagem do $A A$. Eu sei que ele sofreu comigo, uma mãe alcoólica, mas não é suficiente pra ele eu, como exemplo? (Participante 10).

Os trechos revelam que o alcoolismo é um fator que contribui para uma série de repercussões adversas para o gênero feminino, trazendo maior suscetibilidade para o sofrimento e adoecimento.

Estudos avaliam a desvalorização do feminino como provocadora de maior desgaste e percepção de piora na saúde mental, fato que leva à maior procura de mulheres pelos serviços de saúde e mostram também que as mudanças no mundo do trabalho, sobreposição dos papeis (dupla jornada de trabalho) provocam fadiga, estresse e sintomas psíquicos. Além disso, demonstram, também, a relação entre violência doméstica e transtornos mentais (para a Organização Mundial de Saúde é a principal causa vinculada a gênero, que provoca depressão); e consideram que o sofrimento mental duradouro é o que mais provoca busca por consultas em saúde. A dificuldade em detectar as tramas que envolvem gênero e indicadores sociais pode ser notada nos estudos, mesmo que escassos, na área da saúde mental. ${ }^{16}$

O modo como o alcoolista significa o feminino pode estar permeado por sentimentos de raiva, culpa, abandono, dentre outros. Dependendo do contexto, essa relação pode se dar de forma inofensiva, apresentar poucos riscos ou assumir padrões disfuncionais, com prejuízos biológicos, mentais e sociais.

Um conceito do codependente, por exemplo, considera aquele que convive de forma direta com um dependente químico ou a pessoa que, por qualquer motivo, viveu uma prolongada relação parentalizada na família de origem, assumindo, precocemente, responsabilidades inadequadas para a idade e o contexto cultural. ${ }^{17}$

Se considerarmos os codependentes como pessoas que se importam com o outro, que querem amenizar situações e manejar conflitos cogitamos que a mulher assuma, muitas vezes, tal papel. Este tipo de comportamento, dentro da nossa cultura, é valorizado. Desse modo, a mulher tem uma considerável predisposição em assumir um comportamento codependente.

A codependência interfere na vida, notadamente na saúde mental e no modo de lidar com a condição de dependência química. Suas manifestações incluem sofrimento, dor emocional e adoecimento físico e psíquico, refletidos em respostas múltiplas, entre elas: medo, desconfiança, culpa, excesso de cuidado/controle para com o outro, descuido para consigo e mudanças no estilo de vida. Além disso, alguns sentimentos oriundos dessa vivência de codependência são freqüentes, entre eles: descontentamento, incertezas, angústia, depressão, ansiedade, tristeza, desesperança e perda. ${ }^{18}$

Percebemos, ainda, nos discursos dos entrevistados, como é marcante a relação entre feminino, sofrimento e adoecimento, sobretudo quando há a presença de violência.

A passividade e submissão do feminino frente ao masculino se concretizava principalmente por meio de violência, negligência e relações de dependência. As passagens a seguir ilustram os achados.

Os meus dois filhos e minha mulher quase eu matei quando tava embriagado uma vez. Já com homem eu não discutia, tinha medo, eu era um covarde. Uma (hora) da manhã a minha mulher tava trabalhando e eu, bêbado, dizia, quando ela chegava, que ela tava era me traindo com outro (Participante 20).

Minha filha nasceu e eu lembro que nem tinha dinheiro pra levar minha mulher de táxi pro hospital. Eu cheguei bêbado às quatro da manhã em casa, ela tava sentindo as dores e eu tive que levar ela à péaté o hospital. A gente morava perto da José Bastos e o hospital era lá na Bezerra de Menezes. Eu estava sem um tostão no bolso. Já não pensava direito (Participante 19).

Pra nós, homens, eu posso dizer por mim: é difícil de fazer o programa do AA. Imagina então como deve ser difícil pras nossas companheiras. O marido fica em casa enchendo o saco, com ciúme delas. Temos que dar apoio a elas também' (Participante 20).

Historicamente, as mulheres sofrem mais violência física e sexual, além de se envolverem mais em conflitos domésticos do que os homens. Além disso, ao se tratar de morbidade (comprometimentos da saúde e adoecimentos por conta da violência), a mulher é quem mais sofre. $\mathrm{O}$ contraste com as agressões vividas pelas mulheres é, pois, total, já que os homens vivem as várias formas de violência nos espaços públicos e, principalmente entre eles próprios. Nas suas manifestações, esse fenômeno aponta para diferenciais de gênero que respondem 
aos posicionamentos dos sujeitos na sociedade e às identidades construídas nos modos como vivenciam as relações sociais intra-sexo e com o sexo oposto. ${ }^{15}$

O conceito de gênero a que nos reportamos nesse estudo surge enquanto referencial teórico para analisarmos e compreendermos a desigualdade entre o que é atribuído à mulher e ao homem, bem como expectativas geradas sobre o comportamento dos mesmos. Sendo assim, espera-se das mulheres delicadeza, sensibilidade, passividade, subordinação e obediência. E, devido à sua condição biológica de engravidar e amamentar, a sociedade também delegou à mulher o cuidado com o marido, o lar e os filhos, sendo, inclusive, responsabilizada por qualquer coisa de errado que acontece. Por sua vez, os homens estão relacionados ao espaço público, aos papéis de provedor e chefe da casa, à virilidade, coragem e agressividade. Esses papéis sociais, são, na realidade, reforçados pelas culturas patriarcais. ${ }^{19}$

Desse modo, os atributos e papéis de gênero valorizam o homem em detrimento da mulher, legitimando, por um lado, a dominação do homem e, por outro, a inferioridade da mulher. Nesta perspectiva, a mulher é destituída de autonomia e do direito de decidir, inclusive sobre o seu próprio corpo.

Ao final da apresentação dos resultados e discussão, destacamos que os sentidos relativos ao feminino, apreendidos no discurso do alcoolista, colaboram para a saúde mental e constituem fator desencadeante no processo saúde-doença mental, entendido como um processo social caracterizado pelas relações dos sujeitos com a natureza (meio ambiente, espaço, território) e com outros sujeitos (relações sociais, culturais e políticas), num determinado espaço geográfico, e num determinado tempo histórico.

Partindo de uma concepção ampla desse processo e seus determinantes, inserimos o paradigma da promoção da saúde na discussão, já que busca intervir sobre o problema propondo a articulação de saberes técnicos e populares, mobilizando recursos institucionais e comunitários, públicos e privados, visando a capacitação do indivíduo para melhorar e controlar sua saúde. Para alcançar o estado de completo bem-estar físico, mental e social, um indivíduo ou grupo deve ser capaz de identificar aspirações, satisfazer necessidades e mudar ou lidar com seu ambiente. ${ }^{20}$

No contexto estudado, ressaltamos que, para promover saúde, faz-se necessário muito mais do que o acesso a serviços médico-assistenciais de qualidade, é preciso enfrentar os determinantes da saúde em toda a sua amplitude, o que requer políticas públicas favoráveis, uma efetiva articulação intersetorial do poder público e a mobilização da população com vistas à transformação social. ${ }^{21-23}$

\section{CONSIDERAÇÕES FINAIS}

Os dados que obtivemos nos permitem afirmar que, ao mesmo tempo em que é citado como uma fonte de apoio social que traz maior sensação de bem-estar e de oferta de cuidados no decorrer do processo saúde-doença do alcoolista, o feminino associa-se a uma maior suscetibilidade ao sofrimento e ao adoecimento mental, bem como à passividade diante do masculino. Nos relatos, tal sujeição se concretizava por meio da violência, da negligência e das relações de dependência.

Desse modo, os processos sociais envolvendo gênero, no contexto do alcoolismo, repercutem na saúde mental, inclusive, constituindo fator desencadeante no processo saúde-doença mental, que é notoriamente desfavorável ao feminino.

Tais resultados ampliam a compreensão sobre a construção social de gênero e trazem subsídios para a intervenção dos profissionais da saúde num campo, ainda, caracterizado por lacunas, sobretudo no tocante às políticas públicas e práticas profissionais consolidadas, como o da dependência química.

Esse estudo contribui, também, para o desenvolvimento da literatura brasileira que aborda a temática, que se mostra escassa.

Reforçamos que nos voltamos, nessa pesquisa, para a apreensão da subjetividade dos sujeitos, em detrimento da expressão quantitativa do fenômeno estudado, o que o torna limitado no aspecto de generalização dos resultados. Assim, ressaltamos a necessidade de realização de outras investigações que tragam mais subsídios teóricos e práticos, para que profissionais da saúde possam melhor atuar no contexto.

\section{REFERÊNCIAS}

1. Biblioteca Virtual em Saúde. [página na Internet]. 2008. [acesso 2009 Mai 24]. Disponível em: http:/ / decs.bvs.br/cgi-bin/wxis1660.exe/decsserver/

2. Galduróz JC, Noto AR, Nappo S, Carlini EA. I Levantamento domiciliar nacional sobre o uso de drogas psicotrópicas. São Paulo (SP): CEBRID, UNIFESP, SENAD; 2000.

3. Galduróz JC, Noto AR, Nappo S, Carlini EA. II Levantamento domiciliar nacional sobre o uso de drogas psicotrópicas. Brasília (DF): SENAD; 2005. 
4. Paz Filho GJ. Debate sobre o artigo de Delma Pessanha Neves. Cad Saúde Pública. 2004 Jan-Fev; 20(1):25-7.

5. Bardin L. Análise de conteúdo. Lisboa (PT): Edições 70; 1977.

6. Ministério da Saúde (BR), Conselho Nacional de Saúde, Comissão Nacional de Ética em Pesquisa. Resolução No 196 de 10 de outubro de 1996: diretrizes e normas regulamentadoras de pesquisa envolvendo seres humanos. Brasília (DF): MS; 1996.

7. Carlini EA, Galduróz JC, Noto AR, Nappo S. Levantamento domiciliar sobre o uso de drogas psicotrópicas no Brasil: estudo envolvendo as 107 maiores cidades do país: 2001. São Paulo (SP): CEBRID. UNIFESP; 2002.

8. César BAL. O beber feminino: a marca social do gênero feminino no alcoolismo em mulheres. Cad Saúde Coletiva. 2006 Out-Dez; 14(4):583-4.

9. Elbreder MF, Laranjeira R, Siqueira MM, Barbosa DA. Perfil de mulheres usuárias de álcool em ambulatório especializado em dependência química. J Bras Psiquiatr, 2008 Jan, 57(1):9-15.

10. Filizola CLA, Peron CJ, Nascimento MMA, Pavarini SCI, Fernando Filho J. Compreendendo o alcoolismo na família. Esc Anna Nery Rev Enferm. 2006 Dez; 10(4):660-70.

11. Dalgalarrondo P, Corrêa Filho HR, Soldera MA, Silva CAM. Religião e uso de drogas por adolescentes. Rev Bras Psiquiatr, 2004 Jun; 26(2):82-90.

12. Abreu SGSRN. A saúde mental e o apoio social na família do doente oncológico. Porto [tese]. Porto (PT): Instituto de Ciências Biomédicas de Abel Salazar, Universidade do Porto; 2008.

13. Costa AG, Ludermir AB. Transtornos mentais comuns e apoio social: estudo em comunidade rural da Zona da Mata de Pernambuco. Cad Saúde Pública. 2005; 21(1): 73-9.

14. Lima HP. Grupo de auto-ajuda ao alcoolista como dispositivo da rede de apoio social. Fortaleza [dissertação]. Fortaleza (CE): Universidade
Federal do Ceará, Programa de Pós-Graduação em Enfermagem; 2009.

15. Schraiber LB, Gomes R, Couto MT. Homens e saúde na pauta da saúde coletiva. Ciênc Saúde Coletiva. 2005 Jan-Mar; 10(1):7-17.

16. Rabelo IVM, Araújo MF. Violência de gênero na perspectiva da saúde mental. Rev Psicologia Unesp. 2008; 7(1):123-32.

17. Zampieri MAJ. Padrão de codependência e prevalência de sintomas psicossomáticos. [dissertação]. São José do Rio Preto (SP): Faculdade de Medicina de São José do Rio Preto, Mestrado em Medicina e Ciência Correlatas; 2004.

18. Moraes LMP. Atenção de enfermagem ao familiar do dependente químico: grupo como estratégia do cuidar [tese]. Fortaleza (CE): Universidade Federal do Ceará, Programa de Pós-Graduação em Enfermagem; 2008.

19. Gomes NP, Diniz NMF, Araújo AJS, Coelho TMF. Compreendendo a violência doméstica a partir das categorias gênero e geração. Acta Paul Enferm. 2007 Dez; 20(4): 504-8.

20. Ministério da Saúde (BR). Promoção da saúde: Declaração de Alma-Ata, Carta de Ottawa, Declaração de Adelaide, Declaração de Sundsvall, Declaração de Santafé de Bogotá, Declaração de Jacarta, Rede de Megapaíses e Declaração do México. Brasília (DF): MS; 2001.

21. Buss PM. Promoção da saúde e qualidade de vida. Ciênc Saúde Coletiva. 2000 Jan; 5(1);163-77.

22. Czeresnia D. O conceito de saúde e a diferença entre prevenção e promoção. In: Czeresnia D, Freitas CN. Promoção da saúde: conceitos, reflexões, tendências. Rio de Janeiro (RJ): Fiocruz; 2003. p.39-53.

23. Westphal MF. Promoção da saúde e prevenção de doenças. In: Campos GWS, Minayo MCS, Akerman M, Drumond Júnior M, Carvalho YM. Tratado de saúde coletiva. Rio de Janeiro (RJ): Fiocruz; 2006. p. 635-67. 